University of Nebraska - Lincoln

DigitalCommons@University of Nebraska - Lincoln

Faculty Papers and Publications in Animal

Science

Animal Science Department

$5-29-2006$

\title{
Estimates of genetic parameters and genetic trend for reproduction, weight, and wool characteristics of Polypay sheep
}

\author{
Kathryn J. Hanford \\ University of Nebraska, kathy.hanford@unl.edu \\ L. Dale Van Vleck \\ USDA, ARS, US Meat Animal Research Center, Lincoln, NE, dvan-vleck1@unl.edu \\ G.D. Snowder \\ USDA, ARS, US Sheep Experiment Station, Dubois, ID
}

Follow this and additional works at: https://digitalcommons.unl.edu/animalscifacpub

Part of the Animal Sciences Commons

Hanford, Kathryn J.; Van Vleck, L. Dale; and Snowder, G.D., "Estimates of genetic parameters and genetic trend for reproduction, weight, and wool characteristics of Polypay sheep" (2006). Faculty Papers and Publications in Animal Science. 4.

https://digitalcommons.unl.edu/animalscifacpub/4

This Article is brought to you for free and open access by the Animal Science Department at DigitalCommons@University of Nebraska - Lincoln. It has been accepted for inclusion in Faculty Papers and Publications in Animal Science by an authorized administrator of DigitalCommons@University of Nebraska - Lincoln. 


\title{
LIVESTOCK SCIENCE
}

\section{Estimates of genetic parameters and genetic trend for reproduction, weight, and wool characteristics of Polypay sheep ${ }^{\text {tr }}$}

\author{
K.J. Hanford ${ }^{\mathrm{a}, *}$, L.D. Van Vleck ${ }^{\mathrm{b}}$, G.D. Snowder ${ }^{\mathrm{c}, 1}$ \\ a Department of Animal Science, University of Nebraska, A218 Animal Science, Lincoln, NE 68583-0908, United States \\ ${ }^{\mathrm{b}}$ USDA, ARS, US Meat Animal Research Center, Lincoln, NE 68583-0908, United States \\ ${ }^{\mathrm{c}}$ USDA, ARS, US Sheep Experiment Station, Dubois, ID 83423, United States
}

Received 20 December 2004; received in revised form 18 October 2005; accepted 29 November 2005

\begin{abstract}
The objective was to describe genetic parameters and genetic changes in litter sizes at birth and weaning (LB and LW, $n=9081$ ), birth weight (BW, $n=11,896$ ), weaning weight (WW, $n=11,104$ ), fleece weight and grade (FW and FG, $n=8872$ ), and staple length (SL, $n=1805$ ) of Polypay sheep. Direct heritability estimates from single-trait analyses were 0.11 for LB, 0.02 for $\mathrm{LW}, 0.17$ for BW, 0.18 for WW, 0.68 for FW, 0.36 for FG, and 0.76 for SL. Estimates of direct genetic correlation were 0.40 between LB and LW, 0.57 between BW and WW, 0.65 between FW and SL, -0.37 between FW and FG and -0.70 between SL and FG. Breeding values (BV) from both single-trait and seven-trait analyses calculated using the parameters estimated from single-trait and two-trait analyses were compared across years of birth with respect to genetic trends. Estimated BV from both analyses for LB, LW, BW, WW and FW increased over time, while those for FG and SL were unchanged. Estimated changes in BV over time did not differ substantially for single-trait and seven-trait analyses, except for traits highly correlated with another trait that was responding to selection (i.e., LB, which was highly correlated to both LW and WW).
\end{abstract}

(C) 2005 Elsevier B.V. All rights reserved.

Keywords: Genetic correlation; Heritability; Litter size; Prolificacy; Weaning weight

\footnotetext{
Published as paper no. 14877, Journal Ser., Nebraska Agric. Res. Div., Univ. of Nebraska, Lincoln, NE 68583-0908, United States.

* Corresponding author. Tel.: +1 402540 9480; fax: +1 402472 6362 .

E-mail address: khanford2@unl.edu (K.J. Hanford).

${ }^{1}$ Current address: Roman L. Hruska U.S. Meat Animal Research Center, Clay Center, NE 68933-0166, United States.
}

\section{Introduction}

Few long-term selection studies have been conducted with dual-purpose Western range sheep in the U.S. Those that have been conducted, all reported genetic improvement in sheep selected for weaning performance (Burfening et al., 1993; Ercanbrack and Knight, 1998; Sakul et al., 1999). Previous analyses of genetic trends in Columbia, Targhee and Rambouillet sheep, selected over the same timeframe as the Polypay 
sheep considered in this paper, indicated that all three breeds respond favorably to selection for weaning performance (Hanford et al., 2002, 2003, 2005).

The Polypay is a composite breed developed at the United States Sheep Experiment Station (USSES), Dubois, Idaho, USA, in the early 1970s. The breed was developed as a composite breed with the potential for greatly increased reproductive capacity, desirable growth rate and carcass quality (Hulet et al., 1984). Currently there are few estimates of genetic parameters for the Polypay breed. Bromley et al. (2000, 2001) have estimated genetic parameters from data through 1996 from this population. One purpose of this study was to document genetic trends in production traits of the Polypay breed over a 21-year period (1977-1998), where selection has been based on weaning performance under range conditions. The traits analyzed included prolificacy, weight, and wool traits. Because genetic correlations among traits, depending on their strength and direction, may impact estimates of breeding values, another objective was to compare genetic trends for each trait estimated from either a single-trait analysis or from a seven-trait analysis, where genetic correlations are considered.

\section{Materials and methods}

\subsection{Animals and management}

The Polypay breed was developed from crosses of Finnsheep rams by Rambouillet ewes and polled Dorset rams by Targhee ewes followed by matings between these crosses (Hulet et al., 1984). Initially, sheep were selected for number of lambs weaned per year when given two opportunities to lamb each year (twice-a-year lambing). In 1976, the breed was divided into fall and spring lambing groups and selected for litter weight weaned. Randomly bred control lines were maintained for both the fall and spring lambing lines. Two Polypay lines were established in the spring lambing line to be selected from 1976 to 1988 for once-a-year lambing under typical range management conditions (Ercanbrack and Knight, 1998). One of the two lines was selected solely for litter weight weaned (120 days). Ewes were selected annually on current lifetime average litter weight of lamb weaned regressed according to repeatability and number of records. Rams were selected based on their dam's current average litter weight weaned. Rams were selected at approximately 7 months of age and used as sires for only one season. The second line was selected as the first line, except that rams were selected on their dam's current average litter weight weaned and if they exceeded a modest independent culling level of approximately $82 \mathrm{~kg}$ for their own 15-month body weight adjusted for age, type of birth and age of dam. At the end of the study, the two selected lines were combined and selection has continued up to 1998 based on litter weight weaned. The effects of specific selection objectives could not be accounted for because of the rerandomization of breeding animals over the years of this study. The genetic trend in this flock, however, may represent general, but changing, selection emphases of the American sheep industry over this time period.

Under the extensive range management system commonly found in the Rocky Mountains, limiting a ewe to rearing two lambs is a common and wise management practice. This management practice increases overall lamb survival because the total death loss of triplets under extensive range conditions can exceed that of twin reared lambs (Snowder et al., 2001a,b). Therefore, ewes in this study were limited to raising only two of the litter, although a very small percentage of them were allowed to raise three. The results may only apply to similar production systems.

Only records from the spring lambing lines, including the control line, were included in the analyses. The numbers of records per trait, as well as unadjusted means and standard deviations, are presented in Table 1. Ercanbrack and Knight (1998) and Hanford et al. (2002) previously described management of the flock.

\subsubsection{Prolificacy traits}

Litter size at birth was defined as the number of lambs born per ewe exposed in single-sire pen mating. Litter size at weaning was defined as the number of lambs weaned per ewe exposed. Only lambs raised by their own dam were included in litter size at weaning. Numbers of litters, and percentage lamb survival at birth and through weaning, are presented by type of birth in Table 2. Lamb survival rate at birth was high for all types of birth. Survival rate at weaning, however, 
Table 1

Number of records, animals with records, sires and dams of animals with records, years of records, and unadjusted means and standard deviations of prolificacy, weight, and wool traits

\begin{tabular}{|c|c|c|c|c|c|c|}
\hline Trait & Records & Animals with records & Sires & Dams & Years of record & Mean \pm S.D. \\
\hline \multicolumn{7}{|l|}{ Prolificacy traits (trait of ewe) } \\
\hline Litter size at birth ${ }^{\mathrm{a}}$ & 9081 & 3487 & 275 & 1269 & 1978-1998 & $1.77 \pm 0.86$ \\
\hline Litter size at weaning ${ }^{a}$ & 9081 & 3487 & 275 & 1269 & $1978-1998$ & $1.22 \pm 0.78$ \\
\hline \multicolumn{7}{|l|}{ Weight traits (trait of lamb) } \\
\hline Birth weight $(\mathrm{kg})$ & 11,896 & 11,896 & 316 & 2877 & $1977-1998$ & $4.05 \pm 0.78$ \\
\hline Weaning weight (kg) & 11,104 & 11,104 & 316 & 2843 & 1977-1998 & $33.8 \pm 5.8$ \\
\hline \multicolumn{7}{|l|}{ Wool traits (trait of ewe) } \\
\hline Fleece weight $(\mathrm{kg})$ & 8872 & 3415 & 275 & 1262 & $1978-1998$ & $3.48 \pm 0.79$ \\
\hline Fleece grade (U.S. spinning count) ${ }^{b}$ & 8872 & 3415 & 275 & 1262 & $1978-1998$ & $58.2 \pm 2.7$ \\
\hline Staple length $(\mathrm{cm})$ & 1805 & 1805 & 115 & 815 & 1979-1991 & $8.63 \pm 1.47$ \\
\hline
\end{tabular}

${ }^{a}$ Includes records from all ewes exposed to a ram at breeding and present at lambing.

${ }^{\mathrm{b}}$ Spinning counts equivalence to micron system: $54=27.85-29.29 ; 56=26.40-27.84 ; 58=24.95-26.39 ; 60=23.50-24.94 ; 62=22.05-23.49$.

was lower for the lambs born in litters greater than twins. The decrease in survival at weaning to approximately $50 \%$ in the larger litters was largely due to the management practice of restricting ewes to raise only two of the litter. Numbers of ewes, litter size at both birth and weaning, and survival are presented by age of ewe at lambing in Table 3.

\subsubsection{Weight traits}

Birth weight $(\mathrm{kg})$ was recorded for all lambs born alive. Weaning weights $(\mathrm{kg})$ were adjusted to a constant 120 days of age, using individual birth weight and ADG from birth to weaning.

\subsubsection{Wool traits}

Annual greasy fleece weight $(\mathrm{kg})$ and fleece grade (U.S. spinning count) were obtained at shearing in late

Table 2

Number of litters of ewes bred and present at lambing and unadjusted survival rates (percentage of lambs born) at birth and weaning by type of birth

\begin{tabular}{|c|c|c|c|}
\hline \multirow[t]{2}{*}{ Birth type } & \multirow{2}{*}{$\begin{array}{l}\text { Number of litters } \\
\text { (\% of total) }\end{array}$} & \multicolumn{2}{|c|}{ Survival } \\
\hline & & Birth & Weaning \\
\hline Nonpregnant & $768(8.5)$ & - & - \\
\hline Singles & $2249(24.8)$ & 90.0 & 76.8 \\
\hline Twins & $4492(49.5)$ & 93.5 & 75.4 \\
\hline Triplets & $1465(16.1)$ & 90.9 & 54.4 \\
\hline Quadruplets & $104(1.2)$ & 89.2 & 41.3 \\
\hline Quintuplets & $3(0.0)$ & 100.0 & 46.7 \\
\hline
\end{tabular}

May. Fleece grades were subjectively determined by certified graders according to U.S. wool grade standards (Pohle, 1963). Staple length $(\mathrm{cm})$ was measured prior to shearing at midside without stretching the fiber. Staple lengths for yearling ewes were available from 1977 to 1991 . Only wool data from ewes with lambing records were included in these analyses.

\subsection{Statistical analysis}

Table 4 lists both the fixed and random factors included in the statistical models used to estimate (co)variance components for each trait. For each pair of traits, (co)variance components between traits were estimated from two-trait analyses with the models described in Table 4 combined with appropriate covariances between random effects in the model. Breeding values of individual animals were estimated from single-trait analyses and were also estimated from a seven-trait analysis, using the within trait co(variances) from single-trait analyses and between trait covariances from two-trait analyses. Means of estimated breeding values by year of birth were calculated from the seven-trait analysis and compared with the corresponding means of estimated breeding values from single-trait analyses.

Fixed effects included in the model for the prolificacy traits were age of ewe in years at lambing (1-10) and year of lambing (1978-1998). Records of all ewes that were bred and present at lambing were 
Table 3

Number of litters and unadjusted litter sizes of ewes bred and present at lambing and survival rates (percentage of lambs born) at birth and weaning (120 days) by age of ewe at lambing

\begin{tabular}{|c|c|c|c|c|c|c|}
\hline \multirow[t]{2}{*}{ Age (years) } & \multirow{2}{*}{$\begin{array}{l}\text { Number of ewes } \\
\text { (\% of total) }\end{array}$} & \multirow[t]{2}{*}{ Number of litters } & \multicolumn{2}{|c|}{ Litter size $^{\mathrm{a}}$} & \multicolumn{2}{|c|}{ Survival } \\
\hline & & & Birth & Weaning & Birth & Weaning \\
\hline 1 & $2744(30.2)$ & 2313 & 1.23 & 0.74 & 88.3 & 63.3 \\
\hline 2 & $2247(24.7)$ & 2093 & 1.81 & 1.32 & 92.8 & 75.6 \\
\hline 3 & 1453 (16.0) & 1389 & 2.05 & 1.46 & 92.3 & 75.0 \\
\hline $4-6$ & $2259(24.9)$ & 2162 & 2.15 & 1.52 & 94.6 & 74.9 \\
\hline$\geq 7$ & $378(4.2)$ & 356 & 2.08 & 1.36 & 94.9 & 70.1 \\
\hline
\end{tabular}

${ }^{\text {a }}$ Includes records from all ewes exposed to a ram at breeding and present at lambing.

included. Therefore, number of lambs at birth or at weaning could be zero. Analyses of litter size at birth included only parturitions that resulted from singlesire pen matings. Litter size at weaning included only lambs that resulted from single-sire pen matings that were present with their biological mother at weaning. Models for litter size at weaning included the fixed effect of foster code (1, if ewe did not raise a foster lamb; 2, if ewe did raise a foster lamb). Foster lamb records were not included in the record of either the birth dam or the foster dam for litter size at weaning.

The model for birth weight also included the fixed effects of gender of lamb and type of birth (1 to 4), while the model for weaning weight included the fixed effects of gender of lamb and type of birth and rearing. One of the eight types of birth and rearing combinations was assigned to each lamb to account for a lamb born as a single, twin, triplet, or quadruplet, and reared as a single, twin, or triplet.

Table 4

Description of fixed and random factors in animal models associated with prolificacy, weight, and wool traits

\begin{tabular}{|c|c|c|c|}
\hline Trait & Fixed factors & Random factors & Covariate \\
\hline \multirow[t]{2}{*}{ Litter size at birth } & Year of reproduction & Direct genetic (ewe) & \\
\hline & Age of ewe (year) & Permanent environmental (ewe) & \\
\hline \multirow[t]{3}{*}{ Litter size at weaning } & Year of reproduction & Direct genetic (ewe) & \\
\hline & Age of ewe (year) & Permanent environmental (ewe) & \\
\hline & Foster code ${ }^{\mathrm{a}}$ & & \\
\hline \multirow[t]{4}{*}{ Birth weight (kg) } & Year of birth & Direct genetic (lamb) & \\
\hline & Age of dam (year) & Maternal genetic (dam) & \\
\hline & Gender of lamb & Permanent environmental (dam) & \\
\hline & Type of birth & & \\
\hline \multirow[t]{4}{*}{ Weaning weight (kg) } & Year of birth & Direct genetic (lamb) & \\
\hline & Age of dam (year) & Maternal genetic (dam) & \\
\hline & Gender of lamb & Permanent environmental (dam) & \\
\hline & Type of birth and rearing ${ }^{\mathrm{b}}$ & & \\
\hline \multirow[t]{3}{*}{ Fleece weight $(\mathrm{kg})$} & Year of production & Direct genetic (ewe) & Day of year shorn \\
\hline & Age of ewe (year) & Permanent environmental (ewe) & \\
\hline & Number of lambs weaned ${ }^{c}$ & & \\
\hline \multirow[t]{3}{*}{ Fleece grade (U.S. spinning count) } & Year of production & Direct genetic (ewe) & Day of year shorn \\
\hline & Age of ewe (year) & Permanent environmental (ewe) & \\
\hline & Number of lambs weaned ${ }^{c}$ & & \\
\hline \multirow[t]{2}{*}{ Staple length $(\mathrm{cm})$} & Year of production & Direct genetic (yearling ewe) & Day of year shorn \\
\hline & Number of lambs weaned ${ }^{c}$ & & \\
\hline
\end{tabular}

\footnotetext{
${ }^{a}$ Foster code: 1 , if ewe did not raise a foster lamb; 2, if ewe did raise a foster lamb.

${ }^{b}$ One of eight types of birth and rearing combinations was assigned to each lamb to account for a lamb born as a single, twin, triplet, quadruplet, or quintuplet and reared as a single, twin, or triplet.

${ }^{\mathrm{c}}$ For two-trait analyses with litter size at weaning, number of lambs weaned was dropped from the model.
} 
Year of production and number of lambs weaned were included as fixed effects in the model for all three wool traits. Because animals could have more than one measurement for fleece weight and fleece grade, the additional fixed effect of age (year) at shearing was added to the model for these two traits. Julian day of year shorn was included as a linear covariate for all three wool traits.

For two-trait analyses for litter size at weaning with each of the wool traits, the fixed effect of number of lambs weaned included in the model for wool traits was dropped from the model due to apparent confounding with litter size at weaning.

Correlations between permanent environmental effects were estimated between prolificacy traits and wool traits recorded in the same year of production. Estimates of environmental correlations between a ewe's own birth weight, weaning weight, and yearling staple length and her prolificacy and wool traits were calculated with the formula presented by Okut et al. (1999), which forces the covariance between environmental effects into the covariance between permanent environmental effects rather than to the covariance between residual effects when one of the traits is measured more than once. The environmental variance for the single-measured trait was calculated by summing variance components for permanent environmental and residual effects. For pairs of traits measured in the same year for each ewe (litter size at birth, litter size at weaning, fleece weight, and fleece grade), covariances between both permanent and residual effects were estimated from two-trait analyses.

To estimate breeding values jointly for seven traits, estimates of (co)variances from single-trait analyses and estimates of covariances from two-trait analyses were used for the mixed model equations. A $9 \times 9$ genetic (co)variance matrix and an $11 \times 11$ environmental (co)variance matrix were constructed. If the permanent environmental effect was completely confounded with the temporary environmental effect, a fraction of the total environmental variance $(0.0001)$ was arbitrarily assigned to the temporary environmental variance for traits measured only once and the remainder was assigned to the permanent environmental variance (Hanford et al., 2003). Each (co)variance matrix had to be adjusted to be positive definite by applying singular value decomposition to each of the two matrices (Hanford et al., 2003).

A derivative-free REML algorithm (DFREML, Graser et al., 1987) using computer programs of Boldman et al. (1995) was used to estimate (co)variance components. Local convergence was defined as when the variance of the $-2 \log$ likelihoods in the simplex was less than $10^{-6}$. Global convergence was considered attained when the $-2 \log$ likelihoods did not change to the third decimal after restarting.

\section{Results and discussion}

\subsection{Estimates from single-trait analyses}

Estimates of genetic parameters from single-trait analyses for prolificacy, weight, and wool traits are shown in Table 5. Except where noted, estimates of genetic parameters were similar to those reported for Columbia, Targhee, and Rambouillet sheep which were contemporaries of the Polypay at USSES (Hanford et al., 2002, 2003, 2005).

\subsubsection{Prolificacy traits}

Heritability estimates were small, 0.11 for litter size at birth and 0.02 for litter size at weaning. The estimates are similar to estimates previously reported for dual-purpose breeds for litter size at birth (Burfening et al., 1993; Safari and Fogarty, 2003) and to estimates for lambs born per parturition (de Vries et al., 1998; Sakul et al., 1999). The heritability estimate for litter size at weaning is smaller than estimates for the other three contemporary breeds at USSES, other estimates for dualpurpose breeds (Burfening et al., 1993; Safari and Fogarty, 2003) and the heritability estimate for survival to weaning reported by Bradford et al. (1999) for Targhee ewes. This smaller estimate may be due to the management limit on litter size, which did not allow ewes to fully express their genetic potential for the number of lambs they could raise from birth to weaning.

\subsubsection{Weight traits}

Estimates of direct heritability were moderate for both birth weight $(0.17)$ and weaning weight $(0.18)$. 
Table 5

Estimates of genetic parameters and standard errors from single-trait analyses ${ }^{\mathrm{a}}$

\begin{tabular}{|c|c|c|c|c|c|c|}
\hline Trait & $h_{\mathrm{a}}^{2}$ & $h_{\mathrm{m}}^{2}$ & $r_{\mathrm{am}}$ & $p^{2}$ & $e^{2}$ & $\sigma_{\mathrm{p}}^{2}$ \\
\hline \multicolumn{7}{|l|}{ Prolificacy traits (trait of ewe) } \\
\hline Litter size at birth & $0.11 \pm 0.02$ & $\mathrm{ND}^{\mathrm{b}}$ & $\mathrm{ND}^{\mathrm{b}}$ & $0.01 \pm 0.02$ & $0.88 \pm 0.01$ & 0.576 \\
\hline Litter size at weaning & $0.02 \pm 0.01$ & $\mathrm{ND}^{\mathrm{b}}$ & $\mathrm{ND}^{\mathrm{b}}$ & $0.04 \pm 0.01$ & $0.94 \pm 0.01$ & 0.444 \\
\hline \multicolumn{7}{|l|}{ Weight traits (trait of lamb) } \\
\hline Birth weight $(\mathrm{kg})$ & $0.17 \pm 0.02$ & $0.20 \pm 0.03$ & $0.19 \pm 0.11$ & $0.10 \pm 0.01$ & $0.50 \pm 0.02$ & 0.423 \\
\hline Weaning weight $(\mathrm{kg})$ & $0.18 \pm 0.03$ & $0.07 \pm 0.02$ & $0.06 \pm 0.16$ & $0.04 \pm 0.01$ & $0.70 \pm 0.02$ & 21.4 \\
\hline \multicolumn{7}{|l|}{ Wool traits } \\
\hline Fleece weight (kg) & $0.68 \pm 0.03$ & $\mathrm{ND}^{\mathrm{b}}$ & $\mathrm{ND}^{\mathrm{b}}$ & $0.04 \pm 0.02$ & $0.28 \pm 0.01$ & 0.572 \\
\hline Fleece grade (spinning count) & $0.36 \pm 0.02$ & $\mathrm{ND}^{\mathrm{b}}$ & $\mathrm{ND}^{\mathrm{b}}$ & $0.01 \pm 0.01$ & $0.63 \pm 0.01$ & 5.78 \\
\hline Staple length $(\mathrm{cm})$ & $0.76 \pm 0.04$ & $\mathrm{ND}^{\mathrm{b}}$ & $\mathrm{ND}^{\mathrm{b}}$ & $\mathrm{ND}^{\mathrm{c}}$ & $0.24 \pm 0.04$ & 1.69 \\
\hline
\end{tabular}

${ }^{\mathrm{a}} h_{\mathrm{a}}^{2}=$ direct heritability; $h_{\mathrm{m}}^{2}=$ maternal heritability; $r_{\mathrm{am}}=$ correlation between direct and maternal genetic effects; $p^{2}=$ variance due to permanent environmental effects associated with the animal as proportion of total variance, where the animal is the ewe for ewe traits and the dam for lamb traits; $e^{2}=$ variance due to residual effects as proportion of total variance; $\sigma_{\mathrm{p}}^{2}=$ phenotypic variance.

${ }^{\mathrm{b}}$ Maternal effects not included in the model for traits of the ewe.

${ }^{c}$ Permanent environmental effects not included for staple length because the trait was measured only once at 1 year of age.

The estimate of direct heritability for birth weight was within the range of estimates for dual-purpose breeds compiled by Safari and Fogarty (2003) of 0.03 to 0.41 , but greater than the estimate of 0.13 reported by Jurado et al. (1994) for the Merino breed. The estimate of direct heritability for weaning weight was in general agreement with the range of estimates (0.10 to 0.45 ) for dual-purpose breeds for weaning weights measured between 100 and 120 days (Safari and Fogarty, 2003) and to the estimate of 0.19 reported by Al-Shorepy and Notter (1996) for 120day weight.

\subsubsection{Wool traits}

Estimates of direct heritability were $0.68,0.36$, and 0.76 , for fleece weight, fleece grade, and staple length, respectively. These estimates are larger than those reported for fleece weight and staple length for the other three contemporary breeds, while the estimate for fleece grade was higher than the 0.16 reported for the Rambouillet (Hanford et al., 2005). The estimate for fleece weight was higher than the range of estimates ( 0.15 to 0.55$)$ for dual-purpose breeds (Safari and Fogarty, 2003), but similar to the 0.60 reported by Saboulard et al. (1995) for clean fleece weight in western whiteface ewes. The estimate for fleece grade was within the range of estimates ( 0.18 to 0.75 ) for dual-purpose breeds compiled by Safari and Fogarty (2003).

\subsection{Estimates from two-trait analyses}

Estimates of genetic correlations from two-trait analyses among and within groups of prolificacy, weight and wool traits are presented in Table 6 . Except where noted, the estimates were in good agreement with the estimates reported for the contemporary Columbia, Targhee, and Rambouillet by Hanford et al. (2002, 2003, 2005).

\subsubsection{Within prolificacy traits}

The estimate of direct genetic correlation between litter size at birth and litter size at weaning was moderate and positive (0.40). Although it was within the range of estimates (0.29 to 1.00$)$ reviewed by Safari and Fogarty (2003), the estimate was smaller than the estimates reported for the other three contemporary breeds. This difference, in part, may be due to the imposed restriction on the number of lambs that a ewe was allowed to rear if she gave birth to more than two lambs. Although this restriction was applied to all four breeds, the impact would be greater on the more prolific Polypay breed where over $17 \%$ of the births were triplets or greater compared to only $2 \%$ for the other three breeds.

\subsubsection{Within weight traits}

The estimate of direct genetic correlation between birth and weaning weights was moderate and positive 
Table 6

Estimates of genetic and environmental correlations from two-trait analyses between prolificacy, weight, and wool traits ${ }^{\mathrm{a}}$

\begin{tabular}{|c|c|c|c|c|c|c|c|}
\hline Trait 1 & Trait 2 & $r_{\mathrm{g}}$ & $r_{\mathrm{m}}$ & $r_{\mathrm{a}_{1} \mathrm{~m}_{2}}$ & $r_{\mathrm{a}_{2} \mathrm{~m}_{1}}$ & $r_{\mathrm{p}}$ & $r_{\mathrm{e}}$ \\
\hline Litter size at birth & Litter size at weaning & 0.40 & & & & 0.04 & 0.52 \\
\hline Birth weight (kg) & Weaning weight (kg) & 0.57 & 0.48 & -0.01 & 0.23 & 0.70 & 0.39 \\
\hline Fleece weight $(\mathrm{kg})$ & Fleece grade (count) & -0.37 & & & & 0.00 & -0.06 \\
\hline Fleece weight $(\mathrm{kg})$ & Staple length $(\mathrm{cm})$ & 0.65 & & & & $\mathrm{ND}^{\mathrm{b}}$ & 0.01 \\
\hline Fleece grade (count) & Staple length $(\mathrm{cm})$ & -0.70 & & & & $\mathrm{ND}^{\mathrm{b}}$ & -0.04 \\
\hline Litter size at birth & Birth weight (kg) & 0.10 & & -0.03 & & & 0.01 \\
\hline Litter size at birth & Weaning weight $(\mathrm{kg})$ & 0.24 & & -0.04 & & & 0.03 \\
\hline Litter size at weaning & Birth weight $(\mathrm{kg})$ & 0.00 & & 0.40 & & & -0.02 \\
\hline Litter size at weaning & Weaning weight $(\mathrm{kg})$ & 0.07 & & 0.73 & & & -0.01 \\
\hline Litter size at birth & Fleece weight $(\mathrm{kg})$ & -0.26 & & & & 1.00 & -0.06 \\
\hline Litter size at birth & Fleece grade (count) & 0.09 & & & & -1.00 & 0.01 \\
\hline Litter size at birth & Staple length $(\mathrm{cm})$ & -0.05 & & & & $\mathrm{ND}^{\mathrm{b}}$ & 0.04 \\
\hline Litter size at weaning & Fleece weight (kg) & -0.30 & & & & -0.60 & 0.02 \\
\hline Litter size at weaning & Fleece grade (count) & 0.12 & & & & -0.54 & 0.00 \\
\hline Litter size at weaning & Staple length $(\mathrm{cm})$ & -0.35 & & & & $\mathrm{ND}^{\mathrm{b}}$ & 0.01 \\
\hline Birth weight $(\mathrm{kg})$ & Fleece weight (kg) & 0.54 & & & -0.12 & & 0.00 \\
\hline Birth weight $(\mathrm{kg})$ & Fleece grade (count) & -0.03 & & & 0.05 & & 0.00 \\
\hline Birth weight (kg) & Staple length $(\mathrm{cm})$ & 0.17 & & & -0.09 & & 0.00 \\
\hline Weaning weight $(\mathrm{kg})$ & Fleece weight (kg) & 0.18 & & & 0.03 & & 0.29 \\
\hline Weaning weight $(\mathrm{kg})$ & Fleece grade (count) & 0.03 & & & 0.04 & & -0.05 \\
\hline Weaning weight $(\mathrm{kg})$ & Staple length $(\mathrm{cm})$ & 0.02 & & & -0.08 & & 0.19 \\
\hline
\end{tabular}

${ }^{\mathrm{a}} r_{\mathrm{g}}=$ correlation between direct genetic effects; $r_{\mathrm{m}}=$ correlation between maternal genetic effects; $r_{\mathrm{a}_{i} \mathrm{~m}_{j}}=$ correlation between direct additive genetic effect for trait $i$ and maternal genetic effect for trait $j ; r_{\mathrm{p}}=$ correlation between permanent environmental effects (maternal between birth weight and weaning weight and direct between prolificacy and wool traits); $r_{\mathrm{e}}=$ correlation between temporary environmental effects.

$\mathrm{b}$ Permanent environmental effects not included for staple length because the trait was measured only once at 1 year of age.

(0.57) and within the range ( 0.16 to 0.82 ) compiled by Safari and Fogarty (2003) for weaning weights measured between 100 and 120 days. The estimate of maternal genetic correlation between birth weight and weaning weight was also moderately positive (0.48), although slightly smaller than the range $(0.49$ to 0.93 ) compiled by Safari and Fogarty (2003).

\subsubsection{Within wool traits}

Estimates of direct genetic correlations were positive between fleece weight and staple length (0.65) and negative between fleece grade and both fleece weight $(-0.37)$ and staple length $(-0.70)$, in agreement with previous estimates (Saboulard et al., 1995).

\subsubsection{Prolificacy and weight traits}

Estimates of genetic correlations among prolificacy and weight traits ranged from 0.00 between litter size at weaning and birth weight to 0.24 between litter size at birth and weaning weight. The estimate of the genetic correlation between birth weight and litter size at weaning (0.00) was smaller than the estimate (0.34) reported in the review by Fogarty (1995).

The estimate of genetic correlation between litter size at birth and weaning weight (0.24) was smaller than the estimate of 0.49 reported for Rambouillet (Hanford et al., 2005). The estimate of genetic correlation between litter size at weaning and weaning weight (0.07) was also smaller than the estimates for the other three contemporary breeds. This difference, again, may be due to the imposed restriction on the number of lambs that a ewe was allowed to rear.

\subsubsection{Prolificacy and wool traits}

Estimates of genetic correlations between prolificacy traits and wool traits ranged from -0.35 between litter size at weaning and staple length to 0.12 between litter size at weaning and fleece grade. These differed from the small, negative correlations reported for the Rambouillet (Hanford et al., 2005), where they conjectured that the fleece grade of finer-wooled Rambouillet sheep may be more adversely affected by increases in prolificacy than breeds with lower- 


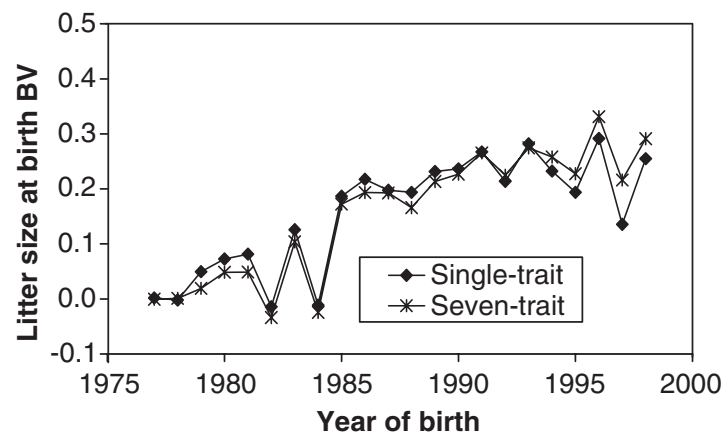

Fig. 1. Means of estimates of breeding value (BV) for litter size at birth by year of birth from single- and seven-trait analyses.

grading fleeces, such as the Columbia, Targhee and Polypay.

\subsubsection{Weight and wool traits}

Estimates of genetic correlations ranged from -0.03 between birth weight and fleece grade to 0.54 between birth weight and fleece weight. Positive correlations for fleece weight with birth and weaning weight ( 0.54 and 0.18 , respectively) suggest some genetic factors influencing animal growth may also influence wool growth.

\subsection{Estimates of genetic change}

Means of estimates of breeding value by year of birth calculated from single-trait analyses and from the seven-trait analysis are plotted in Figs. 1 and 2 for prolificacy traits, in Figs. 3 and 4 for weight traits, and in Figs. 5-7 for wool traits. The means are deviations from the means of estimates of breeding value for

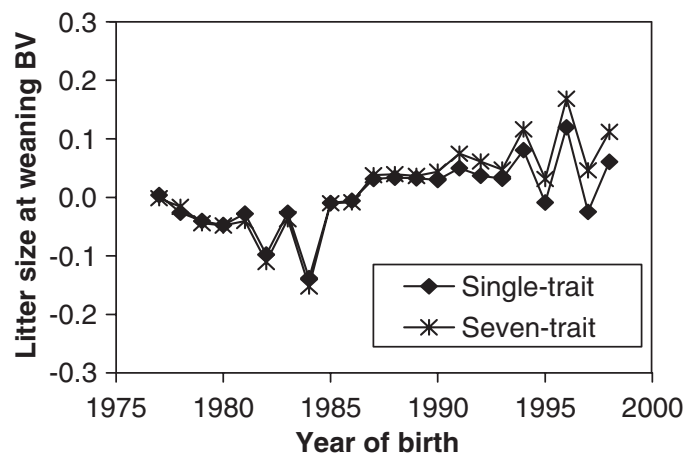

Fig. 2. Means of estimates of breeding value (BV) for litter size at weaning by year of birth from single- and seven-trait analyses.

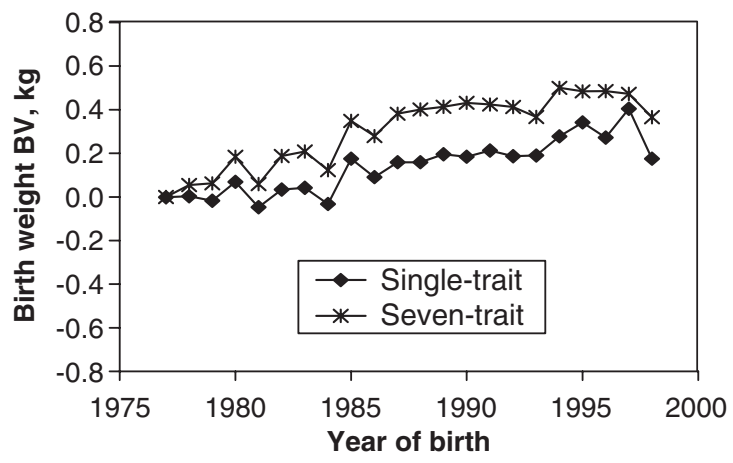

Fig. 3. Means of estimates of breeding value (BV) for birth weight of lambs by year of birth from single- and seven-trait analyses.

animals born in 1977. Except where noted, results were similar to those reported for the contemporary Columbia, Targhee and Rambouillet by Hanford et al. (2002, 2003, 2005).

\subsubsection{Prolificacy traits}

Means of estimates of breeding value by year of birth for litter size at birth from the single-trait analysis and the multiple trait analysis over time were similar (Fig. 1). The mean estimates for litter size at birth increased about 0.3 lambs from 1977 to 1998 . The drops in the breeding values for ewes born in 1982 and 1984 were due to a larger proportion of ewes selected those two years in order to increase the study population. Differences between the single- and seven-trait analyses were greater for the Rambouillet (Hanford et al., 2005).

Means of estimates of breeding value by year of birth for litter size at weaning from the single-trait and

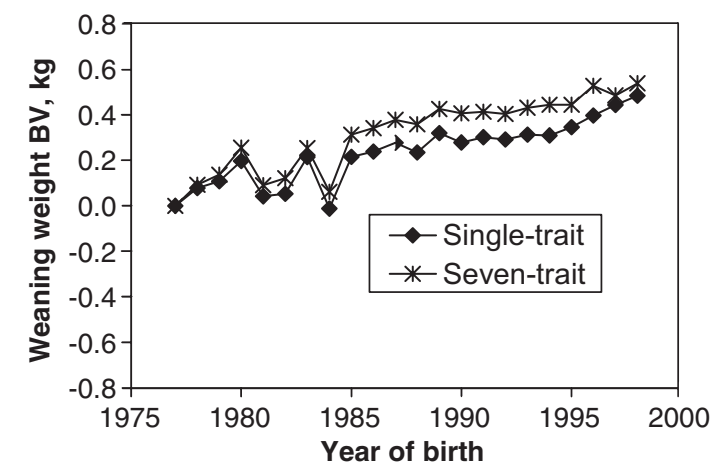

Fig. 4. Means of estimates of breeding value (BV) for weaning weight of lambs by year of birth from single- and seven-trait analyses. 


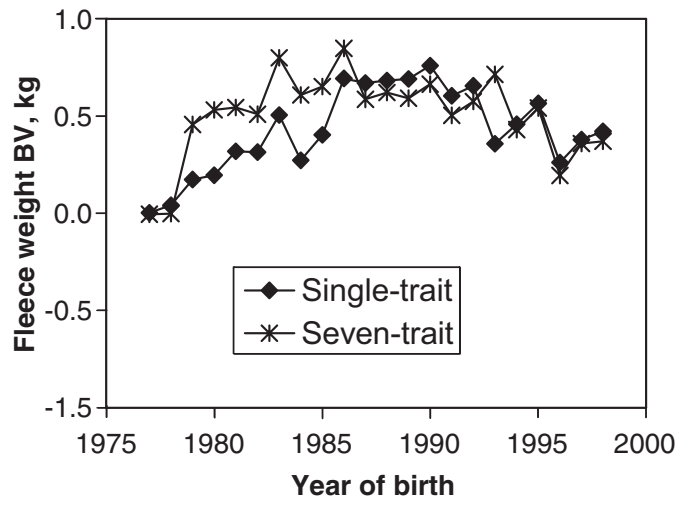

Fig. 5. Means of estimates of breeding value (BV) for fleece weight of ewes and ewe lambs by year of birth from single- and seven-trait analyses.

the seven-trait analyses also were similar over time (Fig. 2). The mean of estimates of breeding value for litter size at weaning increased by 0.1 lambs during the study period, which was smaller than the increase for litter size at birth and smaller than the increases for litter size at weaning for the same time period for the other three breeds. This lack of response in litter size at weaning reported for the Polypay compared to the other breeds, may be due to the differential impact that the management practice of limiting the rearing litter size of a ewe had on the higher prolificacy Polypay breed.

\subsubsection{Weight traits}

Means of estimates of breeding value for birth weight by year of birth from the single-trait analysis

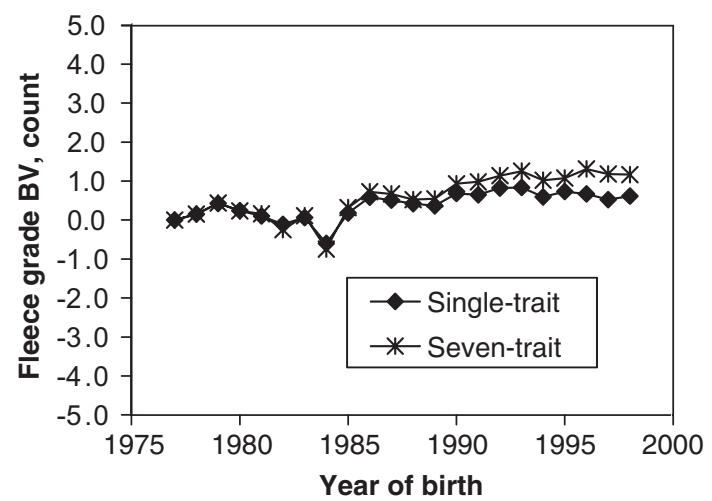

Fig. 6. Means of estimates of breeding value (BV) for fleece grade of ewes and ewe lambs by year of birth from single- and seven-trait analyses.

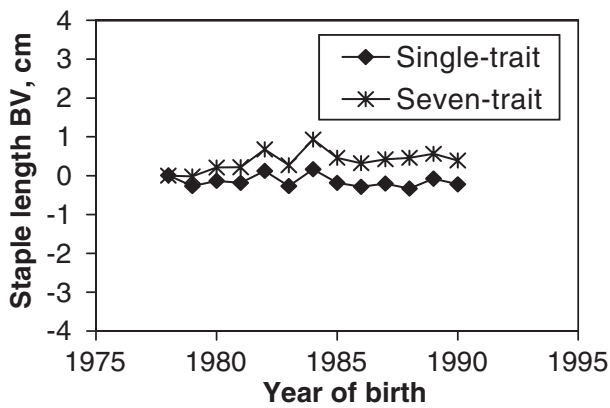

Fig. 7. Means of estimates of breeding value (BV) for staple length of ewe lamb fleeces by year of birth from single- and seven-trait analyses by year of birth.

were slightly less $(0.2 \mathrm{~kg})$ from 1980 to 1998 than means of estimates of breeding value from the seventrait analysis (Fig. 3). This difference was smaller than the difference reported for the Rambouillet (Hanford et al., 2005). Means of estimates of breeding value for birth weight from the single-trait and seven-trait analyses increased about 0.2 and $0.4 \mathrm{~kg}$, respectively, during the study period.

Means of estimates of breeding value for weaning weight by year of birth from single-trait analysis were slightly smaller during the entire study period than means of estimates of breeding value from the seventrait analyses (Fig. 4). This selection response, coupled with the genetic trend for increasing litter size, is highly favorable from an economic perspective. During the 21-year period, the mean of estimates of breeding value increased about $5.0 \mathrm{~kg}$. In comparison with contemporary breeds, genetic trends for weaning weight were similar from single-trait and seven-trait analyses, except for Rambouillet, where the seven-trait means were slightly smaller than the single-trait means (Hanford et al., 2005).

\subsubsection{Wool traits}

Means of estimates of breeding value for fleece weight by year of birth from single-trait analysis were smaller than means from the seven-trait analysis from 1979 to 1986 and in 1993 (Fig. 5). Means for the other years from both single-trait and seven-trait analyses were similar. The smaller means of estimates of breeding value from the single-trait analysis may be due to the large negative genetic correlation of -0.30 between fleece weight and litter size at weaning and large positive genetic correlation of 0.65 between 
fleece weight and staple length used in the seven-trait analysis. Means of estimates of breeding value for litter size at weaning were less than the base year for all the years where the breeding values for fleece weight from the single-trait analysis were smaller than those from the seven-trait analysis. From 1976 to 1986 the means of estimates of breeding value increased by $0.7 \mathrm{~kg}$ from the base year. Means then varied between 0.5 and $0.6 \mathrm{~kg}$ heavier than the base year until about 1993, when means of estimates of breeding value began a decrease to $0.2 \mathrm{~kg}$ above the base year by 1996 , although rebounding to only $0.4 \mathrm{~kg}$ above the base year estimates in 1998 .

Means of estimates of breeding value by year of birth for fleece grade were similar for single-trait and seven-trait analyses (Fig. 6) with differences of less than 2 spinning count from the base year throughout the study period. This genetic trend would be expected for coarse wool sheep breeds where little or no selection is placed on wool quality.

Means of estimates of breeding value for staple length by year of birth for the single-trait analysis did not show any consistent change over time, but means of estimates of breeding for the multiple-trait analysis showed an increase of about $.5 \mathrm{~cm}$ (Fig. 7). This difference may be due to the high positive genetic correlation between staple length and fleece weight (0.65), and fleece weight increased during the study period.

Averages by year of birth did not appear to differ substantially between estimates of breeding values obtained from single-trait and seven-trait analyses for traits not highly correlated with other traits that responded to selection. Estimates of breeding value for birth weight and weaning weight from the seventrait analysis also increased more than estimates from single-trait analyses, which might be due to the high genetic correlation between the traits (0.57). Estimates of genetic correlations less than 0.5 did not have a noticeable impact on means of estimates of breeding value of other traits.

\section{Implications}

Results from this study agree with those of the previous studies of the Columbia, Targhee, and Rambouillet breeds (Hanford et al., 2002, 2003,
2005) that multiple-trait analyses should be used rather than single-trait analyses when estimating genetic changes because of the impact including correlated traits has on estimates of breeding values of other traits. (The former statement seems a strong conclusion when only for birth weight was a persistent advantage of seven-trait as compared to single-trait.) The results also agreed with the previous studies that selection based on weaning performance over a long period could result in a moderate positive response in both litter size at weaning and weaning weight in flocks of dual-purpose breeds. However, a management decision concerning the number of lambs a ewe is allowed to raise can have a greater impact on the response to selection for a prolific breed such as the Polypay, than for less prolific breeds, such as the Columbia, Targhee and Rambouillet. Although most of the correlations between fleece traits and weaning performance were in an undesirable direction, selection for increased weaning performance would offset decreases in wool traits under today's market prices (Snowder, 2002).

\section{References}

Al-Shorepy, S.A., Notter, D.R., 1996. Genetic variation and covariation for ewe reproduction, lamb growth, and lamb scrotal circumference in a fall-lambing sheep flock. J. Anim. Sci. (74), 1490-1498.

Boldman, K.G., Kriese, L.A., Van Vleck, L.D., Van Tassell, C.P., Kachman, S.D., 1995. A manual for the use of MTDFREML. A set of programs to obtain estimates of variances and covariances [DRAFT]. ARS-USDA, Clay Center, NE. 114 pp.

Bradford, G.E., Sakul, H., Dally, M.R., 1999. Selection for weaning weight or litter size in range sheep: II. Correlated responses and effect on productivity. Sheep Goat Res. J. (15), 138-146.

Bromley, C.M., Snowder, G.D., Van Vleck, L.D., 2000. Genetic parameters among growth, prolificacy, and wool traits of Columbia, Polypay, Rambouillet, and Targhee sheep. J. Anim. Sci. (78), 846-858.

Bromley, C.M., Van Vleck, L.D., Snowder, G.D., 2001. Genetic correlations for litter weight weaned with growth, prolificacy, and wool traits in Columbia, Polypay, Rambouillet, and Targhee sheep. J. Anim. Sci. (79), 339-346.

Burfening, P.J., Kachman, S.D., Hanford, K.J., Rossi, D., 1993. Selection for reproductive rate in Rambouillet sheep: estimated genetic change in reproductive rate. Small Rumin. Res. (10), 317-330.

de Vries, M.J., van der Waaij, E.H., van Arendonk, J.A.M., 1998. Estimation of genetic parameters for litter size in sheep: a comparison of a repeatability and a multivariate model. Anim. Sci. (66), 685-688. 
Ercanbrack, S.K., Knight, A.D., 1998. Responses to various selection protocols for lamb production in Rambouillet, Targhee, Columbia, and Polypay sheep. J. Anim. Sci. (76), 1311-1325.

Fogarty, N.M., 1995. Genetic parameters for live weight, fat and muscle measurements, wool production and reproduction in sheep: a review. Anim. Breed. Abstr. (63), 101-143.

Graser, H.-U., Smith, S.P., Tier, B., 1987. A derivative-free approach for estimating variance components in animal models by restricted maximum likelihood. J. Anim. Sci. (64), 1362-1370.

Hanford, K.J., Van Vleck, L.D., Snowder, G.D., 2002. Estimates of genetic parameters and genetic change for reproduction, weight, and wool characteristics of Columbia sheep. J. Anim. Sci. (80), 3086-3098.

Hanford, K.J., Van Vleck, L.D., Snowder, G.D., 2003. Estimates of genetic parameters and genetic change for reproduction, weight, and wool characteristics of Targhee sheep. J. Anim. Sci. (81), $630-640$.

Hanford, K.J., Van Vleck, L.D., Snowder, G.D., 2005. Estimates of genetic parameters and genetic change for reproduction, weight, and wool characteristics of Rambouillet sheep. Small Rumin. Res. (57), 175-186.

Hulet, C.V., Ercanbrack, S.K., Knight, A.D., 1984. Development of the Polypay breed of sheep. J. Anim. Sci. (58), 15-24.

Jurado, J.J., Alonso, A., Alenda, R., 1994. Selection response for growth in a Spanish Merino flock. J. Anim. Sci. (72), 1433-1440.
Okut, H., Bromley, C.M., Van Vleck, L.D., Snowder, G.D., 1999. Genotypic expression at different ages: I. Prolificacy traits of sheep. J. Anim. Sci. (77), 2357-2365.

Pohle, E.M., 1963. Grading and production of wool. In: von Bergen, W. (Ed.), Wool Handbook. John Wiley \& Sons, New York, pp. 547-615.

Saboulard, M., Russell, W.C., Riley, M.L., 1995. Selection for lambing rate and clean fleece weight in sheep. J. Anim. Sci. (73), 3195-3198.

Safari, A., Fogarty, N.M., 2003. Genetic Parameters for Sheep. NSW Agriculture and Australian Sheep Industry CRC.

Sakul, H., Bradford, G.E., Dally, M.R., 1999. Selection for litter size or weaning weight in range sheep: I. Selection practiced and direct response. Sheep Goat Res. J. (15), 126-137.

Snowder, G.D., 2002. Composite trait selection for improving lamb production. Sheep Goat Res. J. (17), 42-48.

Snowder, G.D., Knight, A.D., Van Vleck, L.D., Bromley, C.M., 2001a. Usefulness of subjective ovine milk scores: I. Associations with range ewe characteristics and lamb production. J. Anim. Sci. (79), 811-818.

Snowder, G.D., Van Vleck, L.D., Knight, A.D., Kellom, T.R., Bromley, C.M., 2001b. Usefulness of subjective ovine milk scores: II. Genetic parameter estimates. J. Anim. Sci. (79), $869-876$ 